\title{
Divergent fifteen-year trends in traditional and cardiometabolic risk factors of cardiovascular diseases in the Seychelles
}

\author{
Pascal Bovet*1,2, Sarah Romain², Conrad Shamlaye ${ }^{2}$, Shanti Mendis ${ }^{3}$, \\ Roger Darioli, ${ }^{4}$, Walter Riesen ${ }^{5}$, Luc Tappy ${ }^{6}$ and Fred Paccaud ${ }^{1}$
}

\begin{abstract}
Address: ${ }^{1}$ University Institute for Social and Preventive Medicine (IUMSP) and University Hospital Center, Lausanne, Switzerland, ${ }^{2}$ Ministry of Health and Social Development, Victoria, Republic of Seychelles, ${ }^{3}$ Chronic Disease Prevention and Management, World Health Organization, Geneva, Switzerland, ${ }^{4}$ Lipid Laboratory, University Medical Policlinic, University Hospital Center, Lausanne, Switzerland, ${ }^{5}$ Institute of Clinical Chemistry and Hematology, Canton Hospital, St Gallen, Switzerland and ${ }^{6}$ Department of Physiology, University of Lausanne, Switzerland

Email: Pascal Bovet* - pascal.bovet@chuv.ch; Sarah Romain - dietitian@moh.gov.sc; Conrad Shamlaye - shamlaye@gmail.com; Shanti Mendis - mendiss@who.int; Roger Darioli - roger.darioli@chuv.ch; Walter Riesen - walter.riesen@ikch.ch;

Luc Tappy - luc.tappy@unil.ch; Fred Paccaud - fred.paccaud@chuv.ch

* Corresponding author
\end{abstract}

Published: 26 June 2009

Cardiovascular Diabetology 2009, 8:34 doi:10.1 186/1475-2840-8-34

This article is available from: http://www.cardiab.com/content/8/I/34

(C) 2009 Bovet et al; licensee BioMed Central Ltd.

This is an Open Access article distributed under the terms of the Creative Commons Attribution License (http://creativecommons.org/licenses/by/2.0), which permits unrestricted use, distribution, and reproduction in any medium, provided the original work is properly cited.

\section{Abstract}

Objective: Few studies have assessed secular changes in the levels of cardiovascular risk factors (CV-RF) in populations of low or middle income countries. The systematic collection of a broad set of both traditional and metabolic CV-RF in I989 and 2004 in the population of the Seychelles islands provides a unique opportunity to examine trends at a fairly early stage of the "diabesity" era in a country in the African region.

Methods: Two examination surveys were conducted in independent random samples of the population aged 25-64 years in 1989 and 2004, attended by respectively $108 \mathrm{I}$ and I 255 participants (participation rates $>80 \%$ ). All results are age-standardized to the WHO standard population.

Results: In 2004 vs. 1989, the levels of the main traditional CV-RF have either decreased, e.g. smoking (I7\% vs. 30\%, p<0.00I), mean blood pressure ( $127.8 / 84.8$ vs. $130.0 / 83.4 \mathrm{mmHg}, \mathrm{p}<0.05)$, or only moderately increased, e.g. median LDL-cholesterol ( 3.58 vs. $3.36 \mathrm{mmol} / \mathrm{l}, \mathrm{p}<0.0 \mathrm{I})$. In contrast, marked detrimental trends were found for obesity $(37 \% \mathrm{vs} .2 \mathrm{l} \%, \mathrm{p}<0.00 \mathrm{I})$ and several cardiometabolic CVD-RF, e.g. mean HDL-cholesterol ( $1.36 \mathrm{vs.} \mathrm{I.40} \mathrm{mmol/l,} \mathrm{p}<0.05)$, median triglycerides $(0.80$ vs. 0.78 $\mathrm{mmol} / \mathrm{l}, \mathrm{p}<0.0 \mathrm{l})$, mean blood glucose (5.89 vs. $5.22 \mathrm{mmol} / \mathrm{l}, \mathrm{p}<0.00 \mathrm{I})$, median insulin (I I.6 vs. $8.3 \mu \mathrm{mol} / \mathrm{l}, \mathrm{p}<0.00 \mathrm{I}), \mathrm{median}$ HOMA-IR (2.9 vs. I.8, $\mathrm{p}<0.00 \mathrm{I})$ and diabetes $(9.4 \%$ vs. $6.2 \%, \mathrm{p}<0.00 \mathrm{I})$. At age $40-64$, the prevalence of elevated total cardiovascular risk tended to decrease (e.g. WHO-ISH risk score $\geq 10$; I I\% vs. I3\%, ns), whereas the prevalence of the metabolic syndrome (which integrates several cardiometabolic CVD-RF) nearly doubled ( $36 \%$ vs. $20 \%$, p $<0.00$ I). Data on physical activity and on intake of alcohol, fruit and vegetables are also provided. Awareness and treatment rates improved substantially for hypertension and diabetes, but control rates improved for the former only. Median levels of the cardiometabolic CVD-RF increased between 1989 and 2004 within all BMI strata, suggesting that the worsening levels of cardiometabolic CVD-RF in the population were not only related to increasing BMI levels in the interval.

Conclusion: The levels of several traditional CVD-RF improved over time, while marked detrimental trends were observed for obesity, diabetes and several cardiometabolic factors. Thus, in this population, the rapid health transition was characterized by substantial changes in the patterns of CVD-RF. More generally, this analysis suggests the importance of surveillance systems to identify risk factor trends and the need for preventive strategies to promote healthy lifestyles and nutrition. 


\section{Introduction}

Cardiovascular disease (CVD) is leading the growing burden of chronic noncommunicable diseases (NCD), including in developing countries [1-3]. The good news is that NCDs, and particularly CVD, are largely preventable $[4,5]$. Large cohort studies conducted several decades ago have shown that a large proportion of CVD events could be attributed to three "classical" cardiovascular risk factors (traditional CVD RF: tobacco smoking, raised blood pressure, raised blood cholesterol) [6]. Recent evidence from the INTERHEART study suggests that the relative risk of CVD associated with these CVD RF is fairly constant across populations [7], including in Africa [8].

Correspondingly, diet, physical activity and smoking are key determinants of CVD and other NCDs [9]. For example, the expected impact of combining not smoking, moderate alcohol intake, regular physical activity, and high intake of fruit and vegetables is a $80 \%$ reduction of both CVD and all-cause mortality [10]. Furthermore, the clustering of several risk factors of metabolic origin, which are associated with unhealthy diet, lack of physical activity and overweight, -e.g. increased triglycerides, decreased HDL-cholesterol, impaired fasting glucose, hyperinsulinemia, diabetes- seems to increase vascular risk [11]. The socalled metabolic syndrome is realized when several of these factors are simultaneously present in the same individual: this specific clustering apparently reflects a profound metabolic dysfunction $[12,13]$. The frequency of the metabolic syndrome seems to increase alongside the worldwide raising prevalence of obesity.

The monitoring of population levels of the main CVD-RF and related behaviors is the backbone for surveillance of CVD and other NCDs $[14,15]$. However, reliable information is limited in developing countries. While a number of studies have reported the point prevalence of some CVD$\mathrm{RF}$, few -if any- have provided population-based trends of both traditional and cardiometabolic CVD-RF in the African region. Such data are however crucial to characterize epidemiological changes at population level [16] in order to provide clues on the driving forces of the epidemic of NCDs and to guide prevention and control strategies.

In this study, we report the 15-year trends of a broad set of both the main traditional CVD-RF and several cardiometabolic CVD-RF in the Seychelles, a rapidly developing country in the African region, based on two comprehensive population-based surveys in 1989 and 2004. Of note, previous studies in this population had documented a high CVD mortality [17], a high prevalence of peripheral atherosclerosis [18] and high levels of traditional CVD-RF $[19,20]$. The considered time interval may correspond to a fairly early stage of the "diabesity" epidemic in a middleincome country in epidemiological transition.

\section{Methods}

The Republic of Seychelles is a rapidly developing small island state in the Indian Ocean (African region), east of Kenya and north of Mauritius. The population size was $67^{\prime} 000$ in 1989 (44\% aged $\geq 25$ years) and 84'000 in 2004 ( $57 \%$ aged $\geq 25$ years), which reflects a rapid demographic transition. This underlies the need for age-standardization when comparing results over time. The majority of the population is of African descent. Cardiovascular diseases account for nearly $40 \%$ of total mortality [21]. Life expectancy at birth increased from 63 to 69 years in men and from 73 to 76 years in women between 1989 and 2004 . The gross domestic product (GDP) per capita rose, in real terms, from \$2927 in 1980 to US\$ 5239 in 2004, driven by booming tourism, industrial fishing and services. Health care is available with no fee to all inhabitants through a national health system.

\section{Sampling frame of surveys}

Independent population-based examination surveys of CVD-RF were conducted in $1989[19,22]$ and in 2004 $[20,23]$. For both surveys, the sampling frame consisted of a random sex- and age-stratified sample of the population aged 25-64 years. The samples were drawn from the population of the main island in 1989 (which accounts for $90 \%$ of the total population) and from the entire population in several islands in 2004. Eligible individuals were selected from an electronic database derived from population censuses carried out in 1987 and 2002, regularly updated thereafter by civil status authorities. In 1989, 1309 individuals we sampled; among them 58 were dead or had emigrated at the time of the survey or could not be traced, and 1081 participated in the survey $(86.4 \%)$. In 2004, 1632 individuals were sampled; among them 37 were dead or had emigrated at the time of the survey and 32 could not be traced, and 1255 participated in the survey $(80.2 \%)$. For both surveys, a letter was sent to the eligible participants approximately two weeks prior the appointments to invite them to attend the survey at specified study centers. Other dates for appointments could be arranged and substantial efforts were made to trace the non-participants (e.g. information in the mass media, repeat invitation letters, phone calls, contacts through district administrators, etc). Both surveys were conducted under the auspices of the Ministry of Health, following technical and ethical reviews. Participants gave oral (1989) and written (2004) informed consent.

\section{Measurement of lifestyle-related and clinical variables}

In both surveys, trained officers administered a structured questionnaire on demographic, lifestyle, and other variables to the participants using same or similar questions with regards to the variables considered in this report. Current tobacco use was defined as smoking at least one cigarette every day. Alcohol intake was assessed from a set 
of questions on drinking frequency and volume for the six main available alcoholic beverages (beer, wine/liquor, spirits and three locally made homebrews), taking advantage that only a limited number of brands and contents were available in the country up to 2004. Questions on alcohol were administered to all participants in 1989 but only to the participants who reported to drink at least once a month in 2004 (hence a slight underestimation of alcohol intake in 2004 vs. 1989). Mean daily ethanol intake was calculated. Definitions of "standard units" and "sensible drinking" vary substantially across countries (e.g. http://www.drinkingandyou.com/site/uk/biggy.htm for definitions around the world). A standard unit most often ranges from 8 to $14 \mathrm{~g}$ ethanol per day (or equivalently $10-18 \mathrm{ml}$ ethanol per day) and, in several countries, an intake of ethanol of approximately 1-29 ml/day may correspond to "low risk"; $30-59 \mathrm{ml} /$ day to "moderate risk", and larger intake to "high risk".

Consumption of fruit and vegetables and physical activity was assessed only in 2004 based on the standard STEPS methodology for surveillance of chronic diseases [14,23]. The intake of fruit and vegetables was based on four questions. A daily intake of at least 5 portions of fruit and vegetables is recommended [14]. Physical activity was assessed using the Global Physical Activity Questionnaire (GPAQ), which includes 16 questions assessing the frequency and intensity of physical activity at work, walking to and from places (and not for leisure or work), and physical activity at leisure time [14]. For the calculation, 4 and 8 MET were assigned to the time spent in moderate and vigorous activities, respectively. Light, moderate and high levels of physical activity were defined as $<600,600$ 2999, and $\geq 3000$ MET-minutes per week, respectively [14].

Measurements of clinical variables were made in 1989 and 2004 using largely similar methods. Weight was measured with calibrated medical electronic scales (Seca) and height was measured using fixed stadiometers. Body mass index (BMI) was calculated as weight divided by squared height $\left(\mathrm{kg} / \mathrm{m}^{2}\right)$. Overweight, obesity and extreme obesity were defined for BMI of 25-29, 30-39, and $\geq 40$ $\mathrm{kg} / \mathrm{m}^{2}$, respectively [24]. BP was measured with a mercury sphygmomanometer using a cuff adapted to the arm circumference. BP was based on the two last of three readings taken at intervals of at least 2 minutes, after the participants had been quiet in the study center for at least 30 minutes and was seated for $>10$ minutes. Smoking was not allowed in the study centers. We used the target of $<140 / 90$ mmHg for "controlled" BP [25].

\section{Measurement of biochemical variables}

In both surveys, fasting blood was collected in the early morning, blood was spun at the study centers, and serum was immediately frozen to $-20^{\circ} \mathrm{C}$. For both surveys, participants were requested, in their invitation letter, to fast from midnight, except for water.

Except for blood glucose, all analyses were performed at university laboratories in Switzerland. In 1989, total cholesterol (TC) was measured enzymatically (CHOD-PAP method) using reagents from Boehringer (Manheim, Germany) and high density lipoprotein cholesterol (HDL-C) was similarly measured in the supernatant after precipitation of non HDL lipoproteins with phosphotungstate and $\mathrm{MgCl}^{2}$. In 2004, blood lipids were measured using a Hitachi 917 instrument and Roche reagents. Day-to-day coefficients of variation (CV) were $2.6 \%$ for total cholesterol, $4.1 \%$ for HDL-cholesterol, $4.8 \%$ for triglycerides in 1989 , and 1,8\%, 3.6\%, and 4.5\%, respectively, in 2004 . Low-density lipoprotein cholesterol (LDL-C) was calculated with the Friedewald formula. Total cholesterol $\geq 5.2$ $\mathrm{mmol} / \mathrm{l}(200 \mathrm{mg} / \mathrm{dl})$ and $\geq 6.2 \mathrm{mmol} / \mathrm{l}(240 \mathrm{mg} / \mathrm{dl})$ defines "borderline high" and "high" levels, respectively [26]. Total cholesterol $\geq 8.0 \mathrm{mmol} / \mathrm{l}(\geq 320 \mathrm{mg} / \mathrm{dl}$ ) places a person at high total CVD risk [27]. LDL-cholesterol $\geq 3.4$ $\mathrm{mmol} / \mathrm{l}(130 \mathrm{mg} / \mathrm{dl})$ defines a "borderline high" level. HDL-cholesterol $<1.0 \mathrm{mmol} / \mathrm{l}(40 \mathrm{mg} / \mathrm{dl})$ defines a "low" level (i.e. a risk factor) and a value $\geq 1.5 \mathrm{mmol} / \mathrm{l}(60 \mathrm{mg} /$ $\mathrm{dl})$ defines a "high" level (i.e. a preventive factor) [26]. Triglycerides $\geq 1.7 \mathrm{mmol} / \mathrm{l}(150 \mathrm{mg} / \mathrm{dl})$ define a "borderline-high" level [26].

Fasting blood glucose (FBG) was determined immediately after blood drawing using point-of-care instruments. In 1989 , measurements were made on venous blood using a reflectance meter (Reflomat with Hemoglucotest reagent strips, Boerhinger), a validated and frequently used glucometer at the time, which adapts readings to plasma values [28]. In case of elevated FBG and no diabetes history, a second measurement was made 60-120 minutes later and the last measurement was considered. In 2004, measurements were made on venous blood using a Cholestec LDX analyzer (Cholestec, Haywward, USA), a reliable alternative to conventional laboratory devices [29]; the instrument separates blood cells from plasma and measurements are made on plasma. Coefficients of variation for glycemia was 7.5\% with Reflomat (1989) and $<4 \%$ with Cholestec LDX. In case of FBG and no diabetes history, another measurement was carried out within 10 minutes on capillary blood (Ascentia Elite, Bayer) and the mean of the two values was used. The Ascentia Elite partially adjusts capillary blood readings to plasma values [30]. Hence, although different instruments and sequences were used, methods were fairly similar in 1989 and 2004, making a substantial systematic bias in results in 2004 vs. 1989 unlikely. Impaired fasting blood glucose was defined for FBG of 5.6-6.9 mmol/1 $(100 \mathrm{mg} / \mathrm{dl}-125$ 
$\mathrm{mg} / \mathrm{dl})$ and diabetes for FBG $\geq 7.0 \mathrm{mmol} / \mathrm{l}(126 \mathrm{mg} / \mathrm{dl})$, along current recommendations [31].

Fasting serum insulin (FSI) was measured using commercial radio-immuno assay (RIA) kits (1989: charcoalcoated RIA; 2004: LINCO Research Inc, Missouri, USA). Within-run and day-to-day CV were $<6 \%$ in both 1989 and 2004. The RIA used in 1989 may overestimate insulin concentration in individuals with high concentration of proinsulin or proinsulin splits [32]. HOMA-IR (homeostasis model assessment of insulin resistance) was calculated as [FSI $(\mu \mathrm{U} / \mathrm{ml}) \times \mathrm{FBG}(\mathrm{mmol} / \mathrm{l})] / 22.5][33]$ and has been shown to be a reliable estimate of insulin resistance both among diabetic and non diabetic subjects [34,35].

\section{Cardiovascular disease risk prediction scores}

We calculated different scores to estimate an individual's total CVD risk: a) a simple combination of the main traditional CVD-RF (smoking, high BP and raised cholesterol, or the same and diabetes) and b) the CVD risk prediction score for the African region $\mathrm{D}$ (WHO/ISH risk score). The WHO/ISH risk score was established by the World Health Organization and the International Society of Hypertension and it indicates the ten-year risk of a fatal or non-fatal cardiovascular event (myocardial infarction or stroke) according to age, sex, BP, smoking status, cholesterol level and diabetes status [36,37]. We restricted all score analyses to persons aged $\geq 40$ years because the $\mathrm{WHO} / \mathrm{ISH}$ risk score is not designed for younger individuals (the proportion of persons aged 40-64 in the population of Seychelles constitutes nearly half of the population aged 25-64). We defined the metabolic syndrome according to the updated ATP III criteria [38], however substituting obesity for increased waist circumference, as we did not have waist circumference in 1989 , and considering that a $\mathrm{BMI} \geq 30 \mathrm{~kg} / \mathrm{m}^{2}$ is a criterion used in another definition of the metabolic syndrome [39]. Based on data in 2004, the prevalence of the metabolic syndrome using $\mathrm{BMI} \geq 30 \mathrm{~kg} / \mathrm{m}^{2}$ as a criterion slightly underestimated the prevalence of the syndrome using waist as a criterion (35.8\% based on BMI $\geq 30$ vs. $39.5 \%$ based on increased waist circumference, at age $\geq 40$ ), and the agreement between the two definitions of the metabolic syndrome was high (kappa was $97 \%$ in men and $94 \%$ in women, $\mathrm{p}<0.001$ ).

\section{Statistics}

All prevalences, means and medians reported in this report are weighted for age, separately for 1989 and 2004, using the new World Health Organization standard population [40]. Results in 2004 vs. 1989 can therefore be directly compared (i.e. differences do not reflect the changing age structure of the populations between 1989 and 2004). Means are displayed for variables normally distributed and medians for variables with skewed distri- bution. Differences in means, medians and proportions were tested with ANOVA, rank sum test and chi-square test, respectively. Analyses were performed with Stata 8.2 and $P$ values less than 0.05 were considered significant.

\section{Results \\ Trends in conventional and cardiometabolic risk factors}

Mean age of the participants (upon age standardization) was 42 years (standard deviation: 11) for men and women in both 1989 and 2004. Table 1 shows the trends in BMI, smoking and alcohol intake between 1989 and 2004 as well as the prevalence of categories of physical activity and fruit and vegetable intake in 2004. Mean BMI was higher in women than in men in both surveys and was markedly higher in 2004 than in 1989 in both genders: in 2004, $52 \%$ of men and $68 \%$ of women were overweight or obese. (BMI $\geq 25 \mathrm{~kg} / \mathrm{m}^{2}$ ). The prevalence of cigarette smoking decreased markedly (from $52 \%$ to $31 \%$ in men, from $10 \%$ to $4 \%$ in women). Mean alcohol intake was substantially lower in 2004 than in 1989. Homebrew drinkers had higher ethanol intake from homebrews than drinkers of commercial drinks had from commercial drinks, and these mean alcohol intakes did not change substantially between 1989 and 2004. However, the prevalence of drinkers of homebrews decreased markedly between 1989 and 2004, which contributed to a large decrease in total alcohol intake in 2004 vs. 1989. The prevalence of men and women reporting the recommended amount of $\geq 5$ portions of fruit and vegetables per day (in 2004) was very low. Approximately $80 \%$ of men and women were classified as having either moderate or high physical activity. However, the largest part of this reported physical activity was related to physical activity at work and only $41 \%$ of men and women reported physical activity during their leisure time.

Table 2 shows changes in BP, blood lipids, fasting blood glucose, diabetes, insulin and HOMA-IR between 1989 and 2004. Mean BP slightly decreased over time. The prevalence of persons taking antihypertensive treatment increased greatly over time (from $9 \%$ to $24 \%$ ). The prevalence of "hypertension" (BP $\geq 140 / 90 \mathrm{mmHg}$ or taking antihypertension treatment) was similar in 1989 and 2004). Mean serum total cholesterol levels, which were substantially lower in men than in women in 1989, increased largely over time in men, but only modestly in women, resulting in almost identical levels in men and in women in 2004. Almost two thirds of adults had elevated or high total cholesterol levels $(\geq 5.2 \mathrm{mmol} / \mathrm{l})$ in 2004 . Mean HDL-cholesterol levels were higher in men than in women in 1989. Serum HDL-cholesterol levels were markedly higher in 2004 vs. 1989 in men, consistent with increased prevalence of overweight and decreased alcohol intake during the interval. Mean HDL-cholesterol levels remained virtually unchanged in women. Consequently, 
Table I: Age-standardized trends in body mass index, smoking and alcohol consumption, 1989-2004, and categories of physical activity and fruit and vegetable intake in 2004

\begin{tabular}{|c|c|c|c|c|c|c|c|c|c|}
\hline \multirow[b]{2}{*}{ Value } & \multicolumn{3}{|c|}{ Men } & \multicolumn{3}{|c|}{ Women } & \multicolumn{3}{|c|}{ Total } \\
\hline & 1989 & 2004 & $P$ & 1989 & 2004 & $P$ & 1989 & 2004 & $P$ \\
\hline \multicolumn{10}{|l|}{ Body mass index $\left(\mathrm{kg} / \mathrm{m}^{2}\right)$} \\
\hline mean (SD) & $23.3(3.7)$ & $25.5(4.7)$ & $* * *$ & $25.9(5.7)$ & $28.3(6.3)$ & $* * *$ & $24.6(5.0)$ & $26.9(5.7)$ & $* * *$ \\
\hline$<18.5$ & 8 & 4 & & 3 & 1 & & 5 & 3 & \\
\hline $18.5-24.9$ & 62 & 39 & & 35 & 21 & & 49 & 30 & \\
\hline $25.0-29.9$ & 23 & 33 & & 27 & 26 & & 25 & 30 & \\
\hline $30.0-39.9$ & 6 & 22 & & 32 & 43 & & 19 & 32 & \\
\hline$\geq 40$ & I & 2 & & 3 & 9 & & 2 & 5 & \\
\hline \multicolumn{10}{|l|}{ Daily cigarette smoking } \\
\hline Yes & 50 & 36 & $* * *$ & 10 & 4 & $* * *$ & 30 & 17 & $* * *$ \\
\hline mean cig/day per smoker & 12.7 & 30.8 & $*$ & 6.9 & 8.1 & ns & 11.7 & 10.1 & $*$ \\
\hline \multicolumn{10}{|l|}{ Alcohol intake (ml/day) } \\
\hline mean $(S D)$ & $71(86)$ & $40(62)$ & ** & $9(29)$ & $4(13)$ & $* *$ & $40(81)$ & $22(61)$ & $*$ \\
\hline 0 & 25 & 39 & & 72 & 82 & & 48 & 61 & \\
\hline $1-29$ & 19 & 22 & & 20 & 14 & & 19 & 18 & \\
\hline $30-74$ & 23 & 24 & & 5 & 3 & & 14 & 14 & \\
\hline $75-119$ & 14 & 7 & & 2 & 1 & & 8 & 4 & \\
\hline$\geq 120$ & 20 & 7 & & I & 0 & & II & 4 & \\
\hline \multicolumn{10}{|l|}{ All alcoholic beverages } \\
\hline percent drinkers & 75 & 61 & $* * *$ & 30 & 18 & $* * *$ & 52 & 39 & $* * *$ \\
\hline mean alcohol per drinker & 94.8 & 65.9 & $* * *$ & 30.5 & 20.4 & $*$ & 77.5 & 55.5 & $* * *$ \\
\hline \multicolumn{10}{|l|}{ Commercial alcoholic beverages } \\
\hline percent drinkers & 71 & 58 & $* * *$ & 26 & 18 & $* * *$ & 49 & 38 & $* * *$ \\
\hline mean alcohol per drinker & 40.1 & 41.7 & ns & 16.7 & 17.7 & ns & 33.7 & 36.2 & ns \\
\hline \multicolumn{10}{|l|}{ Homebrews } \\
\hline percent drinkers & 37 & 12 & $* * *$ & 8 & I & $* * *$ & 23 & 6 & $* * *$ \\
\hline mean alcohol per drinker & 114.7 & 135.4 & ns & 44.3 & 41.5 & ns & 104.8 & 126.1 & ns \\
\hline \multicolumn{10}{|l|}{ Fruit and vegetables (\%) } \\
\hline$<3$ portions per day & & 65 & & & 63 & & & 64 & \\
\hline $3-4$ portions per day & & 33 & & & 33 & & & 33 & \\
\hline$\geq 5$ portions per day & & 2 & & & 4 & & & 3 & \\
\hline \multicolumn{10}{|l|}{ Physical activity } \\
\hline \multicolumn{10}{|l|}{ Physical activity at work } \\
\hline percent reporting activitya & & 61 & & & 62 & & & 61 & \\
\hline median MET-min/week & & 2880 & & & 2880 & & & 2880 & \\
\hline \multicolumn{10}{|l|}{ Walking to places } \\
\hline percent reporting activitya & & 57 & & & 71 & & & 64 & \\
\hline median MET-min/week & & 700 & & & 600 & & & 600 & \\
\hline \multicolumn{10}{|c|}{ Physical activity during leisure time } \\
\hline percent reporting activitya & & 41 & & & 41 & & & 41 & \\
\hline median MET-min/week & & 1200 & & & 600 & & & 720 & \\
\hline \multicolumn{10}{|l|}{ Any physical activity (percent) } \\
\hline low $(<600)$ & & 19 & & & 17 & & & 18 & \\
\hline moderate (600-2999) & & 36 & & & 43 & & & 40 & \\
\hline high $(>3000)$ & & 45 & & & 40 & & & 42 & \\
\hline
\end{tabular}

Results are presented as percentage (prevalence), mean or median. ns: not statistically significant; $* p<0.05 ; * * p<0.01$; *** $p<0.001$.

a report physical activity for at least $10 \mathrm{~min}$ at a time during on at least one day per week in the specified domain. 
Table 2: Age-standardized trends in blood pressure, blood lipids, blood glucose, diabetes, insulin and HOMA-IR, I989-2004

\begin{tabular}{|c|c|c|c|c|c|c|c|c|c|}
\hline & \multicolumn{3}{|c|}{ Men } & \multicolumn{3}{|c|}{ Women } & \multicolumn{3}{|c|}{ Total } \\
\hline & 1989 & 2004 & $P$ & 1989 & 2004 & $P$ & 1989 & 2004 & $P$ \\
\hline \multicolumn{10}{|l|}{ BP $(\mathrm{mmHg})$} \\
\hline Systolic (mean) & $133(2 \mid)$ & $131(18)$ & ns & $127(23)$ & $124(19)$ & $*$ & $130(22)$ & $128(19)$ & $* *$ \\
\hline Diastolic (mean) & $87(14)$ & $85(12)$ & $*$ & $83(14)$ & $81(13)$ & ns & $845(14)$ & $83(12)$ & $*$ \\
\hline$<120 / 80$ & 21 & 19 & & 34 & 40 & & 28 & 30 & \\
\hline $120-139 / 80-89$ & 35 & 42 & & 33 & 35 & & 33 & 38 & \\
\hline $140-159 / 90-99$ & 25 & 25 & & 21 & 16 & & 23 & 21 & \\
\hline $160-169 / 100-109$ & 17 & 12 & & 10 & 8 & & 14 & 10 & \\
\hline$\geq 180 / 110$ & 2 & 2 & & 2 & I & & 2 & 1 & \\
\hline$\geq 140 / 90$ or BP treatment & 45 & 44 & & 35 & 36 & & 40 & 40 & \\
\hline \multicolumn{10}{|l|}{ Medication for high BP } \\
\hline Yes & 7 & 21 & $* * *$ & 11 & 26 & $* * *$ & 9 & 24 & $* * *$ \\
\hline \multicolumn{10}{|l|}{ Total cholesterol (mmol/l) } \\
\hline Mean & $5.07(1.10)$ & $5.42(1.26)$ & $* * *$ & $5.33(1.18)$ & $5.40(1.20)$ & ns & $5.20(1.14)$ & $5.41(1.26)$ & $* * *$ \\
\hline$<5.2$ & 60 & 50 & & 48 & 49 & & 55 & 48 & \\
\hline $5.2-6.1$ & 30 & 28 & & 29 & 28 & & 29 & 29 & \\
\hline $6.2-7.9$ & 9 & 20 & & 20 & 20 & & 15 & 20 & \\
\hline$\geq 8.0$ & 1 & 2 & & 3 & 3 & & 2 & 3 & \\
\hline \multicolumn{10}{|l|}{ HDL cholesterol (mmol/l) } \\
\hline Mean & $\mathrm{I} .43(0.5 \mathrm{I})$ & $1.35(0.53)$ & $*$ & $1.38(0.36)$ & $1.36(0.4 I)$ & ns & $\mathrm{I} .40(0.44)$ & $1.36(0.47)$ & $*$ \\
\hline$<1.0$ & 16 & 26 & & 12 & 16 & & 14 & 21 & \\
\hline $1.0-1.4$ & 49 & 43 & & 57 & 50 & & 53 & 47 & \\
\hline$\geq 1.5$ & 35 & 31 & & 31 & 34 & & 33 & 32 & \\
\hline \multicolumn{10}{|l|}{ Triglycerides (mmol/l) } \\
\hline Median & 0.81 & 0.90 & $* *$ & 0.75 & 0.80 & ns & 0.78 & 0.80 & *** \\
\hline$>1.7$ & 12 & 18 & & 6 & 8 & & 9 & 13 & \\
\hline \multicolumn{10}{|l|}{ LDL cholesterol (mmol/l) } \\
\hline Mean & $3.17(1.09)$ & $3.54(1.25)$ & $* * *$ & $3.55(1.10)$ & $3.61(1.16)$ & ns & $3.36(1.11)$ & $3.58(1.20)$ & $* * *$ \\
\hline$\geq 3.4$ & 37 & 50 & & 52 & 53 & & 44 & 52 & \\
\hline \multicolumn{10}{|l|}{ Fasting blood glucose (mmol/l) } \\
\hline Mean & $5.21(1.72)$ & $6.03(2.13)$ & $* * *$ & $5.24(2.19)$ & $5.75(1.81)$ & $* * *$ & $5.22(1.97)$ & 5.89 & $* * *$ \\
\hline$<5.6$ & 76 & 60 & & 78 & 73 & & 77 & 67 & \\
\hline $5.6-6.9$ & 18 & 31 & & 16 & 19 & & 17 & 25 & \\
\hline$\geq 7.0$ & 5.9 & 9.2 & & 5.8 & 7.9 & & 5.8 & 8.5 & \\
\hline$\geq 7.0$ or diabetes treatment & 6.2 & 9.6 & $* * *$ & 6.2 & 9.1 & $* * *$ & 6.2 & 9.4 & $* * *$ \\
\hline \multicolumn{10}{|l|}{ Medication for diabetes } \\
\hline Yes & 1.4 & 4.3 & $*$ & 2.0 & 5.8 & $*$ & 1.7 & 5.0 & ** \\
\hline \multicolumn{10}{|l|}{ Fasting insulin $(\mu \mathrm{mol} / \mathrm{ml})$} \\
\hline Median & 6.8 & 10.5 & $* * *$ & 9.3 & 12.7 & $* * *$ & 8.3 & 11.6 & $* * *$ \\
\hline \multicolumn{10}{|l|}{ HOMA-IR } \\
\hline Median & 1.6 & 2.7 & $* * *$ & 2.0 & 3.1 & $* *$ & 1.8 & 2.9 & $* * *$ \\
\hline$\geq 4.0$ (upper quartile) & 8 & 27 & $* * *$ & 13 & 33 & $* * *$ & II & 30 & $* * *$ \\
\hline
\end{tabular}

Results are presented as percentage (prevalence), mean or median. ns: not statistically significant; $* \mathrm{p}<0.05$; ** $\mathrm{p}<0.01$; *** $\mathrm{p}<0.001$.

mean HDL-cholesterol levels became slightly higher in women than in men in 2004. Median triglyceride levels tended to increase over time (particularly in men). Mean fasting blood glucose levels markedly increased between 1989 and 2004 both in men and women. Approximately one third of men and women had impaired fasting blood glucose levels in 2004 (i.e. FBG between 5.6 and 6.9 $\mathrm{mmol} / \mathrm{l}$ ). The prevalence of diabetes (FBG $\geq 7.0 \mathrm{mmol} / \mathrm{l}$ or glucose lowering treatment) increased by approximately 50\% between 1989 and 2004 (overall: 6.1\% in 1989 to
$9.4 \%$ in 2004). Median levels of fasting serum insulin and HOMA-IR (which reflects insulin resistance) markedly increased over time both in men and women.

The entire age-adjusted distributions of BMI, fasting insulin and fasting glucose markedly shifted toward higher values in 2004 vs. 1989 (Figure 1). There was a trend towards a larger shift in the upper range than lower range for BMI and insulin. For glucose, the shift seemed to be larger for the lower than higher values of the distribution. 

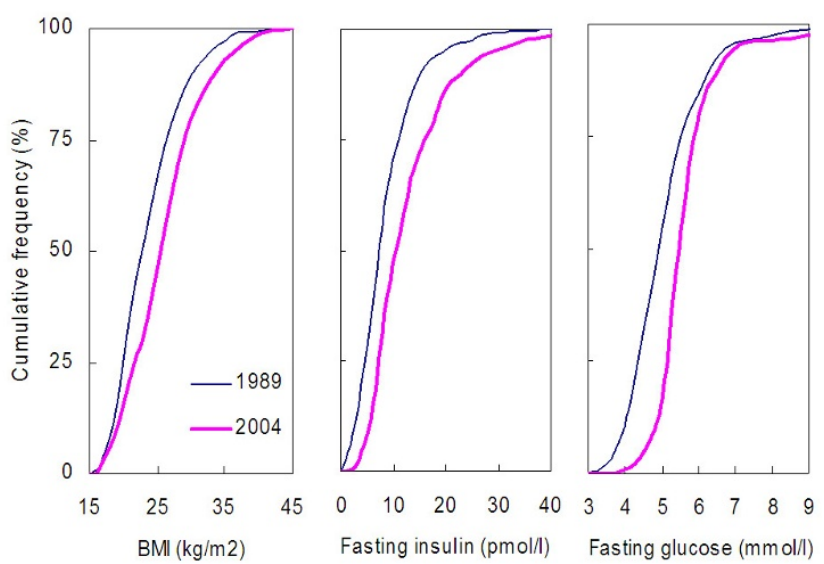

Figure I

Age-standardized cumulative distribution of body mass index, fasting insulin and fasting glucose in 1989 and 2004.

Data are based on all participants, including those treated. Of note, very few diabetic participants were treated with insulin, and oral glucose lowering medications are expected to only minimally lower glucose (e.g. by $\sim 1-2$ $\mathrm{mmol} / \mathrm{l}$ ) as compared to non-treated values. The fairly similar shifts for the three cardiometabolic conditions suggest that these three factors are strongly inter-related.

The proportionate changes in prevalences, in 2004 vs. 1989, were markedly different for the main traditional
CVD-RF vs. the cardiometabolic CVD-RF (Figure 2). For the main three traditional CVD-RF, the prevalence either decreased (smoking), did not substantially change (hypertension, i.e. BP $\geq 140 / 90$ or treatment), or slightly increased (elevated cholesterol). In contrast, the proportionate changes over time were largely unfavorable for overweight and obesity, and for most of the considered metabolic CVD-RF (low HDL-cholesterol, high triglyceride, abnormal fasting glucose, upper quartile of HOMAIR). A larger relative increase in men than in women for most of these obesity-related cardiometabolic CVD-RF is consistent with the proportionately larger increase in overweight/obesity in men than in women. Of note, the absolute increase in mean BMI, between 1989 and 2004, was similar in men $\left(+2.2 \mathrm{~kg} / \mathrm{m}^{2}\right)$ and in women $(+2.4 \mathrm{~kg} /$ $\mathrm{m}^{2}$ ). However, because mean BMI was substantially lower in men than in women in 1989 (with more women than men being already overweight or obese in 1989), the proportionate increase in the prevalence of overweight and obesity, between 1989 and 2004, was greater in men than in women. Of note, mean height changed by less than 0.2 $\mathrm{cm}$ between 1989 and 2004 both in men and women aged 25-64 $(P>0.2)$, hence changes in BMI over time almost entirely reflects increasing weight.

\section{Trends in CVD prediction scores based on traditional and cardiometabolic risk factors}

The age-standardized prevalence of categories with several main traditional CV-RF among men and women aged 4064 years tended to decrease (although not significantly) between 1989 and 2004 (Table 3). Similarly, the preva-

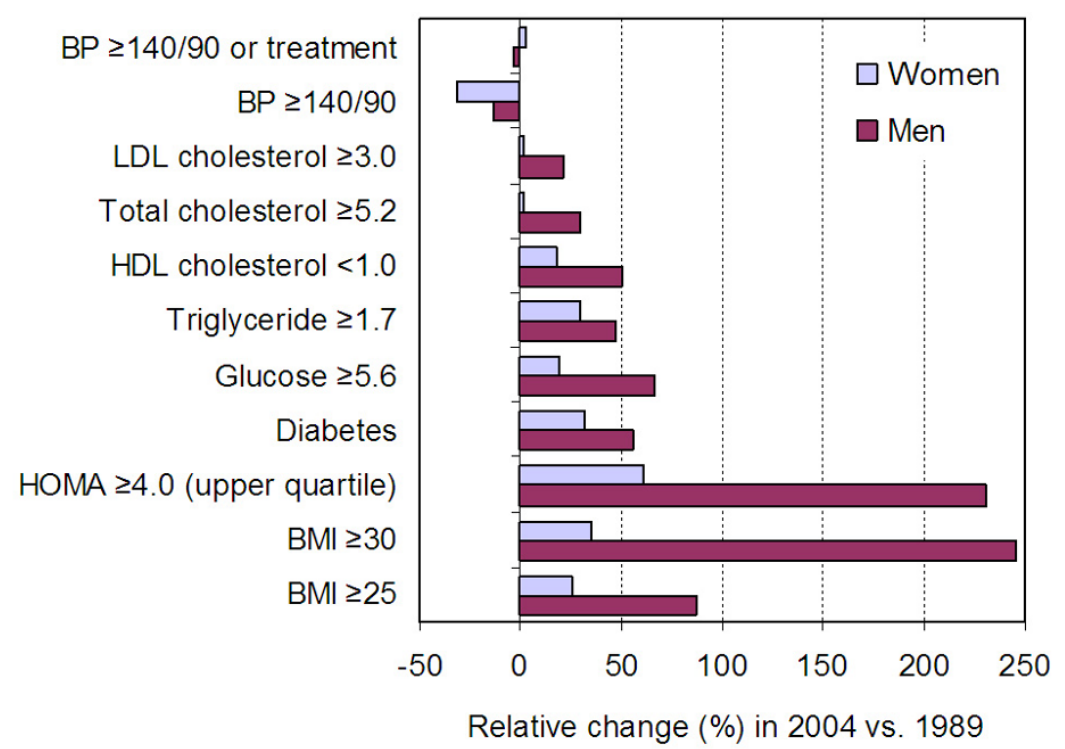

Figure 2

Age-standardized proportionate changes in the prevalence of selected cardiovascular risk factors in 1989 and 2004. 
Table 3: Age-standardized trends in the prevalence of cardiovascular risk prediction scores based on traditional and cardiometabolic risk factors, 1989-2004

\begin{tabular}{|c|c|c|c|c|c|c|c|c|c|}
\hline & \multicolumn{3}{|c|}{ Men } & \multicolumn{3}{|c|}{ Women } & \multicolumn{3}{|c|}{ Total } \\
\hline & 1989 & 2004 & $P$ & 1989 & 2004 & $P$ & 1989 & 2004 & $P$ \\
\hline$\geq \mid$ of 3 traditional risk factors & 93 & 90 & ns & 83 & 81 & ns & 88 & 85 & ns \\
\hline$\geq 2$ of 3 traditional risk factors & 55 & 47 & ns & 43 & 36 & $*$ & 49 & 42 & $* *$ \\
\hline 3 of 3 traditional risk factors & 10 & 8 & ns & 2 & 1 & $*$ & 6 & 5 & ns \\
\hline$\geq 1$ of 4 traditional risk factors & 93 & 90 & ns & 84 & 82 & ns & 88 & 86 & ns \\
\hline$\geq 2$ of 4 traditional risk factors & 57 & 51 & ns & 43 & 41 & ns & 50 & 46 & ns \\
\hline$\geq 3$ of 4 traditional risk factors & 14 & 17 & ns & 10 & 10 & ns & 12 & 13 & ns \\
\hline 4 of 4 traditional risk factors & 3 & 2 & ns & 1 & 0 & ns & 2 & I & ns \\
\hline $\mathrm{WHO} / \mathrm{ISH}$ score AFRO $\geq 10$ & 14 & 11 & ns & 13 & 11 & ns & 13 & 11 & ns \\
\hline $\mathrm{WHO} / \mathrm{ISH}$ score AFRO $\geq 20$ & 7 & 5 & ns & 4 & 5 & ns & 6 & 5 & ns \\
\hline Metabolic syndrome & 13 & 32 & $* * *$ & 26 & 40 & $* * *$ & 20 & 36 & $* * *$ \\
\hline
\end{tabular}

ns: not statistically significant; $* p<0.05$; ** $p<0.01$; *** $p<0.001$.

DM: diabetes mellitus. WHO/ISH score AFRO: CVD risk prediction score for the African region D.

Major risk factors (3): blood pressure $\geq 140 / 90 \mathrm{mmHg}$ or treatment; daily smoking; total cholesterol $\geq 5.2 \mathrm{mmol} / \mathrm{l}$.

Major risk factors (4): same as above + diabetes (fasting blood glucose $\geq 7.0 \mathrm{mmol} / \mathrm{l}$ or treatment).

Metabolic syndrome using ATP III criteria modified with BMI $\geq 30 \mathrm{~kg} / \mathrm{m}^{2}$ instead of elevated waist circumference.

lence of men and women with elevated total CVD risk, based on the WHO/ISH risk score, tended to decrease both in men and in women (except for women with a score $\geq 20$ ). In contrast, the prevalence of the metabolic syndrome increased greatly in men $(13 \%$ to $32 \%, \mathrm{P}<$ $0.001)$ and in women ( $26 \%$ to $40 \%, \mathrm{P}<0.001)$.

\section{Awareness, treatment and control rates for high blood pressure, diabetes and dyslipidemia}

Awareness, treatment and control rates increased markedly over time for high BP (Table 4). For diabetes, awareness increased markedly, and almost all persons aware of diabetes were treated in 2004, but the control rates among treated persons remained low. For high cholesterol (data available only in 2004), awareness and treatment remained low in 1989 and 2004 but control was high among the few persons treated (reflecting the high efficacy

Table 4: Age-standardized trends (in \%) in awareness, treatment and control of high blood pressure, diabetes and hypercholesterolemia, 1989-2004

\begin{tabular}{|c|c|c|c|c|c|c|c|c|c|}
\hline & \multicolumn{3}{|c|}{ Men } & \multicolumn{3}{|c|}{ Women } & \multicolumn{3}{|c|}{ All } \\
\hline & $\begin{array}{c}\text { Aware among } \\
\text { all with } \\
\text { condition }\end{array}$ & $\begin{array}{l}\text { Treated } \\
\text { among } \\
\text { aware }\end{array}$ & $\begin{array}{l}\text { Controlled } \\
\text { among } \\
\text { treated }\end{array}$ & $\begin{array}{c}\text { Aware } \\
\text { among all } \\
\text { with HBP }\end{array}$ & $\begin{array}{l}\text { Treated } \\
\text { among } \\
\text { aware }\end{array}$ & $\begin{array}{l}\text { Controlled } \\
\text { among } \\
\text { treated }\end{array}$ & $\begin{array}{c}\text { Aware } \\
\text { among all } \\
\text { with HBP }\end{array}$ & $\begin{array}{l}\text { Treated } \\
\text { among } \\
\text { aware }\end{array}$ & $\begin{array}{c}\text { Controlled } \\
\text { among } \\
\text { treated }\end{array}$ \\
\hline \multicolumn{10}{|c|}{ High blood pressure (BP $\geq 140 / 90 \mathrm{mmHg}$ or treated) } \\
\hline 1989 & 36 & 41 & 9 & 49 & 63 & 16 & $4 I$ & 52 & 14 \\
\hline 2004 & 55 & 89 & 24 & 75 & 96 & 42 & 64 & 93 & 34 \\
\hline$P$ & $* * *$ & $* * *$ & $* * *$ & $* * *$ & $* * *$ & $* * *$ & $* * *$ & $* * *$ & $* * *$ \\
\hline \multicolumn{10}{|c|}{ Diabetes (fasting blood glucose $\geq 7.0 \mathrm{mmol} / \mathrm{l}$ or treated) } \\
\hline 1989 & 36 & 64 & 28 & 44 & 75 & 24 & 40 & 70 & 26 \\
\hline 2004 & 46 & 97 & 15 & 64 & 100 & 26 & 54 & 98 & 21 \\
\hline$P$ & ns & $* *$ & ns & $*$ & $* *$ & ns & $*$ & $* * *$ & ns \\
\hline \multicolumn{10}{|c|}{ High total cholesterol ( $\geq 6.2 \mathrm{mmol} / \mathrm{l}$ or treated $)$} \\
\hline 1989 & - & - & - & - & - & - & - & - & - \\
\hline 2004 & 9 & 24 & 78 & II & 28 & 42 & 10 & 26 & 57 \\
\hline
\end{tabular}

ns: not statistically significant; $* \mathrm{p}<0.05 ; * * \mathrm{p}<0.0$ I; *** $\mathrm{p}<0.00$ I.

Proportions (in \%) are from total for "aware"; from aware for "treated", and from treated for "controlled".

Cut off values for "Controlled" are BP <140/90 mmHg for "high blood pressure", fasting blood glucose <7.0 mmol/l for "diabetes", and cholesterol $<6.2 \mathrm{mmol} / \mathrm{l}$ for "high total cholesterol". 
of atorvastatin, which was the lipid-lowering medication used most often in the Seychelles in 2004).

\section{Trends in traditional and cardiometabolic risk factors within BMI categories}

Stratified analysis of CVD-RF levels within BMI categories allows determining whether the secular changes in traditional and cardiometabolic CVD-RF in 2004 vs. 1989 were independent of the increase in BMI in the interval (Table 5). All the considered traditional and metabolic CVD-RF increased, as expected, across increasing categories of $\mathrm{BMI}$. Within the same BMI categories, median systolic and diastolic BP decreased over time (irrespective of antihypertension medication) but the median levels of several metabolic CVD-RF (particularly fasting blood glucose and insulin) substantially increased over time, suggesting a role of factors other than BMI to account for the increasing levels of the cardiometabolic CVD-RF in 2004 vs. 1989.

\section{Discussion}

The major finding of this study is that the population levels of the main traditional CVD-RF either decreased (smoking, high blood pressure) or only slightly increased (elevated total cholesterol) during the considered 15-year interval, while the levels of several cardiometabolic CVDRF (diabetes, high triglyceride, low HDL-cholesterol, and high HOMA-IR) markedly increased in a country in rapid health transition in the African region. Correspondingly, the prevalence of persons with elevated total CVD risk (using a CVD risk prediction score largely based on the main traditional CVD-RF) tended to decrease over time, whereas the prevalence of the metabolic syndrome doubled. These findings further suggest that the secular increase in adiposity is driving secular changes in the cardiometabolic risk profile in this population.
Several observations can be made in relation to the rather favorable secular trends in several main traditional CVD$\mathrm{RF}$. The large decrease in the prevalence of tobacco use reflects sustained tobacco control programs during the past decade in the Seychelles, including a ban on tobacco advertisement, increasingly high taxes on cigarettes, and continuous education programs in the mass media [41]. The slight secular downward trend in systolic/diastolic BP is less easy to explain. While treatment and control rates for hypertension markedly increased over time, and alcohol intake decreased, the prevalence of several other determinants of high BP increased, e.g. overweight, insulin resistance and, possibly, sedentary habits. A separate study indicated moderate salt consumption in the Seychelles ( $\sim 5$ grams per day) [42], consistent with a staple diet based on fish and rice. Hence, protective, unaccounted factors may override the impact of rising determinants of BP.

The slight increase in total cholesterol and LDL-cholesterol may relate to a shift from the traditional diet largely made of rice and fish to increased consumption of meat and processed foods. This deterioration in blood lipids levels in the population is fairly small compared to other developing countries [43]: this may relate to the already fairly high cholesterol levels in the Seychelles in 1989 and, perhaps, a shift toward an increasing consumption of vegetable oils low in saturated fats (e.g. corn oil) and a decreasing consumption of palm oil (rich in saturated fats), despite slightly higher prices of the former. This might be attributable to health education programs in the Seychelles, which have repeatedly emphasized on this nutritional issue.

The largest secular change in CVD-RF was observed for overweight and obesity. This is consistent with marked socio-economic changes in the recent decades in the Seychelles, including increased purchasing power (the GDP

Table 5: Age-standardized trends in median levels of traditional and cardiometabolic risk factors according to body mass index

\begin{tabular}{|c|c|c|c|c|c|c|c|c|c|}
\hline & \multicolumn{3}{|c|}{$\mathrm{BMI}<25$} & \multicolumn{3}{|c|}{ BMI 25-29 } & \multicolumn{3}{|c|}{$\mathrm{BMI} \geq 30$} \\
\hline & 1989 & 2004 & $P$ & 1989 & 2004 & $P$ & 1989 & 2004 & $P$ \\
\hline Systolic BP (mmHg) & 122 & 120 & $*$ & 132 & 127 & $* * *$ & 138 & $13 \mid$ & $* * *$ \\
\hline Diastolic BP (mmHg) & 80 & 79 & $*$ & 89 & 84 & $* * *$ & 90 & 86 & $* * *$ \\
\hline Systolic BP, not treated $(\mathrm{mmHg})$ & 120 & 118 & $* * *$ & 130 & 122 & $* * *$ & 134 & 126 & $* * *$ \\
\hline Diastolic BP, not treated $(\mathrm{mmHg})$ & 80 & 77 & $* * *$ & 87 & 81 & $* * *$ & 88 & 84 & $* * *$ \\
\hline LDL-cholesterol $(\mathrm{mmol} / \mathrm{l})$ & 2.98 & 3.23 & $* *$ & 3.66 & 3.61 & ns & 3.86 & 3.67 & ns \\
\hline HDL-cholesterol (mmol/l) & 1.39 & 1.48 & $*$ & 1.28 & 1.19 & ns & 1.24 & 1.19 & ns \\
\hline Triglyceride (mmol(l) & 0.71 & 0.73 & ns & 0.93 & 0.94 & ns & 0.94 & 0.98 & ns \\
\hline Glucose $(\mathrm{mmol} / \mathrm{l})$ & 4.6 & 5.2 & $* * *$ & 5.0 & 5.5 & $* * *$ & 5.2 & 5.6 & $* * *$ \\
\hline Insulin $(\mu \mathrm{mol} / \mathrm{l})$ & 6.9 & 8.7 & $* * *$ & 9.7 & 12.8 & $* * *$ & 13.3 & 16.9 & $* * *$ \\
\hline
\end{tabular}

All data are expressed as median values.

ns: not statistically significant; $* \mathrm{p}<0.05$; ** $\mathrm{p}<0.00$ I; *** $\mathrm{p}<0.001$. 
per capita doubled in 2004 vs. 1989), larger caloric intake, and increasing sedentary behaviors. For examples, calorie availability per capita increased from 1800 to 2300 over the past 20 years [44] and the local production of carbonated soft drinks has tripled in the past 25 years (figures from Seychelles Breweries Ltd). During the same period, the numbers of private cars and passengers transported by buses have doubled (figures from the Licensing Authority and from the Seychelles Public Transport Company).

The association between adiposity, insulin resistance and metabolic CVD-RF are well known $[12,13]$. We previously showed that insulin resistance was associated with serum triglycerides (directly) and HDL-cholesterol (inversely) in the population of Seychelles [45]. We also described, in this population, a high prevalence of the metabolic syndrome in 2004, irrespective of the definition used [46]; a strong relationship between insulin resistance and BMI, independent of blood glucose impairment [47]; and an association between pre-diabetes and increased artery intima-media thickness [48]. More generally, it is well recognized that the increasing prevalence of obesity is a main driving force behind the rising prevalence of several cardiometabolic CVD-RF, including insulin resistance and diabetes, in populations worldwide $[11,49,50]$. In our study, the prevalence of overweight and obesity increased proportionately more in men than in women, and so did the levels of several cardiometabolic CVD-RF (although the secular increase in mean BMI was similar, in absolute values, in both genders). This suggests that an increase in the population levels of cardiometabolic CVD-RF may be more sensitive to BMI changes at intermediary vs. high levels. Interestingly, stratified analysis suggested that factors other than adiposity (as measured by BMI, in our study) also accounted for the increasing levels of the cardiometabolic CVD-RF over time.

What is the significance of our observed divergent secular trends in traditional vs. cardiometabolic CVD-RF in the population? Based on a review of all death certificates, the age-adjusted mortality rates for stroke and myocardial infarction (per 100'000 total population) were fairly high by international standards, e.g. 92/69 in men/women for stroke and 64/28 for myocardial infarction in 2002-2005 [17]. However, the rates in 2002-2005 were 15-30\% lower than in 1989-1992 [17]. These downward CVD mortality trends are consistent with decreasing levels of several traditional CVD-RF and decreasing prevalence of high total CVD risk (based on CVD risk prediction scores). This also means that the detrimental trends in cardiometabolic CVD-RF had little detrimental impact on CVD mortality. This may relate to several factors. First, we previously showed that the slope of the relationship between BP and BMI had decreased in 2004 vs. 1989, irrespective of anti-hypertension treatment [51], suggesting a secular decreasing impact of BMI on BP. Similarly, we found that BP decreased during the past decade among children despite a marked increase in the prevalence of overweight [52]. A decreased impact of adiposity over time has also been observed in other populations: both the relative risk of CVD associated with obesity and the mean levels of traditional CVD-RF within BMI strata decreased over time (except for diabetes) in the USA between 1970 and 2000 [53,54].

The discrepancy between the favorable trends in both CVD mortality [17] and predicted CVD mortality (based on the WHO/ISH risk score in this study), on one hand, and the markedly unfavorable trends in cardiometabolic CVD-RF, on the other hand, seems to dismiss a large impact of the cardiometabolic CVD-RF (and insulin resistance) on CVD outcomes, at a population level. There is ongoing controversy on the value of the metabolic syndrome as a physiopathological and clinical concept able to enhance our understanding and our management of CVD risk in patients and in populations. It is not yet clear whether the metabolic syndrome improves the prediction of CVD risk as compared to traditional CVD-RF [55]; if it predicts CVD incidence better than its individual components [55-58]; or even if it performs better than fasting blood glucose for predicting diabetes [58]. However, a time lag may be necessary before this metabolic wave translates into detrimental cardiovascular outcomes in the population. This could explain why the decline in CVD rates only recently flattened (among young adults) in western countries, despite decades of increasing prevalence of obesity [59]. A time lag had also been suggested for the effect of traditional CVD-RF on the incidence of CVD [60]. Alternatively, a detrimental impact related to the increased prevalence of several cardiometabolic CVD$\mathrm{RF}$ and, in particular, increasing insulin resistance in the population might be offset, in our study, by the favorable trends in several major traditional CVD-RF.

These uncertainties regarding the actual impact of obesity and the metabolic syndrome on the incidence of CVD should not lead to overlook the fully acknowledged link between obesity and diabetes. The tide of diabesity is worrying when considering the continuously poor control rates among treated diabetic persons -in contrast to control of hypertension or dyslipidemia. This finding points to the known difficulty to control cardiometabolic conditions because of insulin resistance [61], a situation that should likely result in an increased burden of diabetesrelated complications. The unfavorable impact of the rising levels of cardiometabolic CVD-RF on the burden of diabetes-related diseases is illustrated, in the Seychelles, by the increasing proportion of diabetic patients in chronic hemodialysis (approximately a third of all patients under chronic hemodialysis in 2004) and the 
increasing incidence of diabetes-related amputations recorded at hospital.

There are a few limitations in the study. Laboratory methods were similar, but not identical, in 1989 and 2004, which is inevitable since laboratory methods and instruments change over time. However, except for blood glucose, all biochemical analyses were done at university laboratories using best practices at their time. Furthermore, the consistency in i) the observed secular detrimental changes for all the considered cardiometabolic CVDRF (e.g. HDL-cholesterol, triglyceride, glucose, insulin) and ii) the good concordance between the proportionate changes in the prevalence of obesity and the proportionate changes in the mean levels of the considered cardiometabolic CVD-RF in men vs. women, suggests coherence in the results. From an epidemiological perspective, one must refrain to equate the category of "high $\mathrm{BP}$ or treatment" (BP $\geq 140 / 90 \mathrm{mmHg}$ or antihypertensive treatment) to "hypertension", since BP measurements based on only one occasion (like in our study) can substantially overestimate the true prevalence of hypertension [62]. The same remark applies, to a lesser extent, to "elevated blood glucose or treatment" vs. "diabetes". Strong points of the study include the fairly large sample sizes, the truly random selection of the participants, the large participation rates, the comprehensive assessment of both traditional and cardiometabolic CVD-RF, the largely similar methods used in the two surveys and, most importantly, the availability of such data in a country in the African region as early as in 1989 (i.e. at a fairly early stage of the diabesity era).

Our findings have several implications for public health. Overall, the rather favorable secular trends in several main traditional CVD-RF are consistent with the downward trends in age-standardized CVD mortality in this population [17]. This is consistent with downward age-specific trends observed in the western countries [63] and -to a lesser extent- in some developing countries as well [64]. The decreasing smoking prevalence and the improved treatment rates for hypertension in Seychelles are likely related to the national multipronged program against chronic diseases since the early 1990s $[41,65]$. However, the levels of these major traditional CVD-RF remain high in the population. There is therefore a continued need for public health interventions to further reduce levels of smoking, BP and blood cholesterol in the population $[66,67]$ and for strengthening health services for improved health care of high-risk individuals [68]. On the other hand, the prevalence of obesity and related cardiometabolic CVD-RF have dramatically increased during the past 15 years, which may stem from global social and economic changes that fuel unhealthy nutrition and physical inactivity [69]. The significance of these epidemiolog- ical changes on the incidence of CVD cannot be evaluated yet in our data - and further studies will be needed to address this question-, but their impact on the prevalence of diabetes and its complications is already visible. This latter observation is the main reason to take the upward trends in obesity and diabetes in developing countries as a major public health challenge [70]. Since individualcentered approaches for weight prevention and control have limited impact [71], emphasis should be given to policy and structural interventions that promote regular physical activity and healthy nutrition in the entire population [50,72-76]. Finally, our data emphasize the importance of reliable and standardized information systems to identify the changing epidemiological situation and to guide, monitor and evaluate the clinical and public health responses.

\section{Competing interests}

The authors declare to have no competing interests. The views expressed in this paper are solely the responsibility of the named authors and do not necessarily reflect the views of the institution(s) to which they are affiliated.

\section{Authors' contributions}

PB was the principal investigator of both surveys and led the data analysis and the write up of the manuscript; CS and FP participated to the study design of both surveys and reviewed the manuscript; RD, WR and LT performed most of the biochemical analyses and reviewed the manuscript; SR and SM participated to the interpretation of the data and reviewed the manuscript. All authors read and approved the final manuscript.

\section{Acknowledgements}

The authors thank all the participants to the surveys and acknowledge the coordinating roles in the surveys of J. Quilindo, O. Choisy, J. Tsang Kwai Kew, J. William-Fostel, G. Madeleine, and B. Viswanathan. Special thanks to the Ministry of Health, Republic of Seychelles for continuing support to epidemiological research, in particular the ministers in charge of health since 1989: R. Adam, J. Dugasse, P. Pillay, V. Meriton, M.S. Mondon and M.-P. Lloyd.

\section{Funding}

The following institutions provided funding and/or resources for the surveys: the Ministry of Health, Republic of Seychelles (1989 and 2004); the Department of Cooperation, Jura Canton, Switzerland (1989); several departments at the University Hospital of Lausanne (CHUV), Switzerland (I989 and 2004), including the Institute of Social and Preventive Medicine (IUMSP), the Medical Policlinic, and the Department of Physiology; the Institute of Clinical Chemistry and Hematology, Canton Hospital, St Gallen, Switzerland (2004); and the World Health Organization (2004). Several private or parastatal companies in the Seychelles also provided support, in particular the Seychelles Marketing Board with vouchers given to all the participants (2004); and Air Seychelles and SkyChef Seychelles Ltd for international transport of equipment and blood samples (1989 and 2004). 


\section{References}

I. Yusuf S, Reddy S, Ounpuu S, Anand S: Global burden of cardiovascular diseases: part I: general considerations, the epidemiologic transition, risk factors, and impact of urbanization. Circulation 200I, I 04:2746-2753.

2. Lopez AD, Mathers CD, Ezzati M, Jamison DT, Murray C): Global and regional burden of disease and risk factors, $200 \mathrm{I}$ : systematic analysis of population health data. Lancet 2006, 367: $1747-1757$.

3. Abegunde DO, Mathers CD, Adam T, Ortegon M, Strong K: The burden and costs of chronic diseases in low-income and middle-income countries. Lancet 2007, 370:1929-1938.

4. Maciosek MV, Coffield AB, Edwards NM, Flottemesch TJ, Solberg LI: Prioritizing Clinical Preventive Services: A Review and Framework with Implications for Community Preventive Services. Annu Rev Public Health 2009 in press.

5. Kottke TE, Faith DA, Jordan CO, Pronk NP, Thomas RJ, Capewell S: The comparative effectiveness of heart disease prevention and treatment strategies. Am / Prev Med 2009, 36:82-88.

6. Stamler J, Stamler R, Neaton JD, Wentworth D, Daviglus ML, Garside D, Dyer AR, Liu K, Greenland P: Low risk-factor profile and longterm cardiovascular and noncardiovascular mortality and life expectancy: findings for 5 large cohorts of young adult and middle-aged men and women. JAMA I999, 282:2012-20I8.

7. Yusuf S, Hawken S, Ounpuu S, Dans T, Avezum A, Lanas F, McQueen M, Budaj A, Pais P, Varigos J, Lisheng L, INTERHEART Study Investigators: Effect of potentially modifiable risk factors associated with myocardial infarction in 52 countries (the INTERHEART study): case-control study. Lancet 2004, 364:937-952.

8. Steyn K, Sliwa K, Hawken S, Commerford P, Onen C, Damasceno A, Ounpuu S, Yusuf S, INTERHEART Investigators in Africa: Risk factors associated with myocardial infarction in Africa: the INTERHEART Africa study. Circulation 2005, I | 2:3554-356 I.

9. lestra JA, Kromhout D, Schouw YT van der, Grobbee DE, Boshuizen $H C$, van Staveren WA: Effect size estimates of lifestyle and dietary changes on all-cause mortality in coronary artery disease patients: a systematic review. Circulation 2005, I I 2:924-934.

10. Khaw KT, Wareham N, Bingham S, Welch A, Luben R, Day N: Combined impact of health behaviours and mortality in men and women: the EPIC-Norfolk prospective population study. PLoS Med 2008, 5:el2.

II. Grundy SM, Cleeman JI, Daniels SR, Donato KA, Eckel RH, Franklin BA, Gordon DJ, Krauss RM, Savage PJ, Smith SC Jr, Spertus JA, Costa F, American Heart Association; National Heart, Lung and Blood Institute: Diagnosis and management of the metabolic syndrome: an American Heart Association/National Heart, Lung, and Blood Institute Scientific Statement. Circulation 2005, I I 2:2735-2752.

12. Reaven GM: Banting lecture 1988. Role of insulin resistance in human disease. Diabetes 1988, 37:1595-1607.

13. Ferrannini E, Haffner SM, Mitchell BD, Stern MP: Hyperinsulinaemia: the key feature of a cardiovascular and metabolic syndrome. Diabetologia 1991, 34:416-422.

14. Chronic diseases and health promotion - STEPwise approach to surveillance (STEPS) Geneva: WHO; 2009.

15. The WHO Global InfoBase Geneva: World Health Organization; 2009.

16. Vlasoff T, Laatikainen T, Korpelainen V, Uhanov M, Pokusajeva S, Rogacheva A, Tossavainen K, Vartiainen E, Puska P: Ten year trends in chronic disease risk factors in the Republic of Karelia, Russia. Eur J Public Health 2008, 18:666-673.

17. Bovet P, Junker C, Michel P, Paccaud F: Decreasing stroke and myocardial infarction mortality in a country of the African region. Circulation 2007, 38(2):535.

18. Perret F, Bovet P, Shamlaye C, Paccaud F, Kappenberger L: High prevalence of peripheral atherosclerosis in a rapidly developing country. Atherosclerosis 2000, I53:9-2I.

19. Bovet P, Shamlaye C, Kitua A, Riesen WF, Paccaud F, Darioli R: High prevalence of cardiovascular risk factors in the Seychelles (Indian Ocean). Arterioscler Thromb 1991, I I:I730-I736.

20. Bovet P, Shamlaye C, Gabriel A, Riesen W, Paccaud F: Prevalence of cardiovascular risk factors in a middle-income country and estimated cost of a treatment strategy. BMC Public Health 2006, 6:9.

21. Statistical abstracts Victoria, Seychelles: Management \& Information Systems Division; 2005.
22. Bovet P, Rosalie D, Shamlaye C, Darioli R, Paccaud F: The Seychelles cardiovascular diseases survey 1989. Soz Praventivmed I991, 36(SuppI I):S3-S7.

23. Bovet $P$, William J, Viswanathan B, Romain S, Yerly P, Paccaud F, Gabriel A: The Seychelles Heart Study 2004: methods and main findings 2007 [http://www.who.int/chp/steps/ 2004 STEPS Report Seychelles.pdf]. Victoria, Seychelles: Ministry of Health and Social Development

24. Clinical guidelines on the identification, evaluation, and treatment of overweight and obesity in adults: executive summary. Expert Panel on the Identification, Evaluation, and Treatment of Overweight in Adults. Am J Clin Nutr 1998 , 68:899-917.

25. Chobanian AV, Bakris GL, Black HR, Cushman WC, Green LA, Izzo JL Jr, Jones DW, Materson BJ, Oparil S, Wright JT Jr, Roccella EJ, National Heart, Lungand Blood Institute Joint National Committee on, Prevention, Detection, Evaluation, and Treatment of High Blood Pressure; National High Blood Pressure Education Program Coordinating Committee: The Seventh Report of the Joint National Committee on Prevention, Detection, Evaluation, and Treatment of High Blood Pressure: the JNC 7 report. JAMA 2003, 289:2560-2572.

26. Executive Summary of The Third Report of The National Cholesterol Education Program (NCEP) Expert Panel on Detection, Evaluation, And Treatment of High Blood Cholesterol In Adults (Adult Treatment III). JAMA 200I, 285:2486-2497.

27. Fourth Joint Task Force of the European Society of Cardiology and Other Societies on Cardiovascular Disease Prevention in Clinical Practice (Constituted by representatives of nine societies and by invited experts): European guidelines on cardiovascular disease prevention in clinical practice: executive summary. Eur Heart J 2007, 28:2375-24|4.

28. Brunton WA, Steel JM, Percy-Robb IW: An assessment of a reflectance meter system for measurement of plasma or blood glucose in the clinic or side ward. Clin Chim Acta 1977, 75:359-364.

29. Shemesh T, Rowley KG, Shephard M, Piers LS, O'Dea K: Agreement between laboratory results and on-site pathology testing using Bayer DCA2000+ and Cholestech LDX point-ofcare methods in remote Australian Aboriginal communities. Clin Chim Acta 2006, 367:69-76.

30. Rheney CC, Kirk JK: Performance of three blood glucose meters. Ann Pharmacother 2000, 34:317-32I.

31. Diagnosis and classification of diabetes mellitus. Diabetes Care 2009, 32(Suppl I):S62-S67

32. Temple RC, Carrington CA, Luzio SD, Owens DR, Schneider AE, Sobey WJ, Hales CN: Insulin deficiency in non-insulin-dependent diabetes. Lancet 1989, I:293-295.

33. Matthews DR, Hosker JP, Rudenski AS, Naylor BA, Treacher DF, Turner RC: Homeostasis model assessment: insulin resistance and beta-cell function from fasting plasma glucose and insulin concentrations in man. Diabetologia 1985, 28:412-419.

34. Bonora E, Targher G, Alberiche M, Bonadonna RC, Saggiani F, Zenere $M B$, Monauni T, Muggeo $M$ : Homeostasis model assessment closely mirrors the glucose clamp technique in the assessment of insulin sensitivity: studies in subjects with various degrees of glucose tolerance and insulin sensitivity. Diabetes Care 2000, 23:57-63.

35. Ikeda Y, Suehiro T, Nakamura T, Kumon Y, Hashimoto K: Clinical significance of the insulin resistance index as assessed by homeostasis model assessment. Endocr J 200I, 48:8I-86.

36. Mendis S, Lindholm LH, Mancia G, Whitworth J, Alderman M, Lim S, Heagerty T: World Health Organization (WHO) and International Society of Hypertension (ISH) risk prediction charts: assessment of cardiovascular risk for prevention and control of cardiovascular disease in low and middle-income countries. J Hypertens 2007, 25: I578-I 582.

37. Prevention of cardiovascular disease. Guidelines for assessment and. management of total cardiovascular risk Geneva: World Health Organization; 2007.

38. Grundy SM, Cleeman JI, Daniels SR, Donato KA, Eckel RH, Franklin BA, Gordon DJ, Krauss RM, Savage PJ, Smith SC Jr, Spertus JA, Costa $F$ : Diagnosis and management of the metabolic syndrome: an American Heart Association/National Heart, Lung, and 
Blood Institute Scientific Statement. Circulation 2005, I I 2:2735-2752

39. Alberti KG, Zimmet PZ: Definition, diagnosis and classification of diabetes mellitus and its complications. Part I: diagnosis and classification of diabetes mellitus provisional report of a WHO consultation. Diabet Med 1998, 15:539-553.

40. Ahmad OB, Boschi-Pinto C, Lopez AD, Murray CJL, Lozano R, Inoue M: Age standardization of rates: a new WHO standard Geneva: World Health Organization; 2005.

41. Viswanathan B, Warren CW, Jones NR, Asma S, Bovet P: Linking Global Youth Tobacco Survey (GYTS) data to the WHO Framework Convention on Tobacco Control (FCTC): the case for the Seychelles. Prev Med 2008, 47(Suppl I):S33-S37.

42. Bochud M, Bovet P, Elston RC, Paccaud F, Falconnet C, Maillard M, Shamlaye C, Burnier M: High heritability of ambulatory blood pressure in families of East African descent. Hypertension 2005, 45:445-450.

43. Critchley J, Liu J, Zhao D, Wei W, Capewell S: Explaining the increase in coronary heart disease mortality in Beijing between I 984 and 1999. Circulation 2004, I I 0: | 236- I 244.

44. Food and Agriculture Organization of the United Nations. (FAO), Food Balance Sheets [http://faostat.fao.org/site/502/ default.aspx]

45. Bovet $P$, Faeh $D$, Gabriel $A$, Tappy $L$ : The prediction of insulin resistance with serum triglyceride and high-density lipoprotein cholesterol levels in an East African population. Arch Intern Med 2006, 166:1236-1237.

46. Kelliny C, William J, Riesen W, Paccaud F, Bovet P: Metabolic syndrome according to different definitions in a rapidly developing country of the African region. Cardiovasc Diabetol 2008, 7:27.

47. Faeh D, William J, Tappy L, Ravussin E, Bovet P: Prevalence, awareness and control of diabetes in the Seychelles and relationship with excess body weight. BMC Public Health 2007, 7:163.

48. Faeh D, William J, Yerly P, Paccaud F, Bovet P: Diabetes and prediabetes are associated with cardiovascular risk factors and carotid/femoral intima-media thickness independently of markers of insulin resistance and adiposity. Cardiovasc Diabetol 2007, 6:32

49. Grundy SM: Obesity, metabolic syndrome, and cardiovascular disease. I Clin Endocrinol Metab 2004, 89:2595-2600.

50. Ingelsson E, Arnlov J, Sundstrom J, Riserus U, Michaelsson K, Byberg $\mathrm{L}$ : Relative importance and conjoint effects of obesity and physical inactivity for the development of insulin resistance. Eur J Cardiovasc Prev Rehabil 2009, 16:28-33.

5I. Danon-Hersch N, Chiolero A, Shamlaye C, Paccaud F, Bovet P. Decreasing association between body mass index and blood pressure over time. Epidemiology 2007, 18:493-500.

52. Chiolero A, Paradis G, Madeleine G, Hanley JA, Paccaud F, Bovet P. Discordant secular trends in elevated blood pressure and obesity in children and adolescents in a rapidly developing country. Circulation 2009, I 19:558-565.

53. Flegal KM, Graubard BI, Williamson DF, Gail MH: Excess deaths associated with underweight, overweight, and obesity. JAMA 2005, 293: $|86|-1867$

54. Gregg EW, Cheng YJ, Cadwell BL, Imperatore G, Williams DE, Flegal KM, Narayan KM, Williamson DF: Secular trends in cardiovascular disease risk factors according to body mass index in US adults. JAMA 2005, 293: I868-1874.

55. Wannamethee SG, Shaper AG, Lennon L, Morris RW: Metabolic syndrome vs Framingham Risk Score for prediction of coronary heart disease, stroke, and type 2 diabetes mellitus. Arch Intern Med 2005, 165:2644-2650.

56. Ford ES: Risks for all-cause mortality, cardiovascular disease, and diabetes associated with the metabolic syndrome: a summary of the evidence. Diabetes Care 2005, 28: 1769-1778.

57. Gami AS, Witt BJ, Howard DE, Erwin PJ, Gami LA, Somers VK, Montori VM: Metabolic syndrome and risk of incident cardiovascular events and death: a systematic review and metaanalysis of longitudinal studies. J Am Coll Cardiol 2007, 49:403-4I4.

58. Sattar N, McConnachie A, Shaper AG, Blauw GJ, Buckley BM, de Craen AJ, Ford I, Forouhi NG, Freeman DJ, Jukema JW, Lennon L, Macfarlane PW, Murphy MB, Packard CJ, Stott DJ, Westendorp RG, Whincup PH, Shepherd J, Wannamethee SG.: Can metabolic syndrome usefully predict cardiovascular disease and diabetes?
Outcome data from two prospective studies. Lancet 2008, 37I:1927-1935.

59. O'Flaherty M, Ford E, Allender S, Scarborough P, Capewell S: Coronary heart disease trends in England and Wales from 1984 to 2004: concealed levelling of mortality rates among young adults. Heart 2008, 94:178-18।.

60. Rose G: Incubation period of coronary heart disease. 1982. Int J Epidemiol 2005, 34:242-244.

6I. Saydah SH, Fradkin J, Cowie CC: Poor control of risk factors for vascular disease among adults with previously diagnosed diabetes. JAMA 2004, 291:335-342.

62. Bovet P, Gervasoni JP, Ross AG, Mkamba M, Mtasiwa DM, Lengeler C, Bovet P, Gervasoni JP, Ross AG, Mkamba M, Mtasiwa DM, Lengeler C: Assessing the prevalence of hypertension in populations: are we doing it right? J Hypertens 2003, 2 I:509-5 I7.

63. Luepker RV: Decline in incident coronary heart disease: why are the rates falling? Circulation 2008, I I 7:592-593.

64. Rodriguez T, Malvezzi M, Chatenoud L, Bosetti C, Levi F, Negri E, La Vecchia C: Trends in mortality from coronary heart and cerebrovascular diseases in the Americas: 1970-2000. Heart 2006, 92:453-460.

65. Bovet P, Shamlaye H, Paccaud F: Epidemiology and prevention of cardiovascular disease in the Seychelles islands (Indian Ocean). CVD Prevention 1999, 2:261-272.

66. Asaria P, Chisholm D, Mathers C, Ezzati M, Beaglehole R: Chronic disease prevention: health effects and financial costs of strategies to reduce salt intake and control tobacco use. Lancet 2007, 370:2044-2053.

67. Gaziano TA, Galea G, Reddy KS: Scaling up interventions for chronic disease prevention: the evidence. Lancet 2007, 370:1939-1946.

68. Lim SS, Gaziano TA, Gakidou E, Reddy KS, Farzadfar F, Lozano R, Rodgers A: Prevention of cardiovascular disease in high-risk individuals in low-income and middle-income countries: health effects and costs. Lancet 2007, 370:2054-2062.

69. Misra $A$, Khurana $L$ : Obesity and the metabolic syndrome in developing countries. I Clin Endocrinol Metab 2008, 93:59-30.

70. Hossain P, Kawar B, El Nahas M: Obesity and diabetes in the developing world - a growing challenge. N Engl J Med 2007, 356:213-215.

7I. Katan MB: Weight-loss diets for the prevention and treatment of obesity. N Engl J Med 2009, 360:923-925.

72. Byberg L, Melhus H, Gedeborg R, Sundstrom J, Ahlbom A, Zethelius $B$, Berglund LG, Wolk A, Michaëlsson K: Total mortality after changes in leisure time physical activity in $\mathbf{5 0}$ year old men: 35 year follow-up of population based cohort. BMJ 2009, 338:b688.

73. Kumanyika SK, Obarzanek E, Stettler N, Bell R, Field AE, Fortmann SP, Franklin BA, Gillman MW, Lewis CE, Poston WC, Stevens J, Hong $Y$, American Heart Association Council on Epidemiology and Prevention, Interdisciplinary Committee for Prevention: Population-based prevention of obesity: the need for comprehensive promotion of healthful eating, physical activity, and energy balance: a scientific statement from American Heart Association Council on Epidemiology and Prevention, Interdisciplinary Committee for Prevention (formerly the expert panel on population and prevention science). Circulation 2008, I I 8:428-464.

74. Action Plan for the Global Strategy for the Prevention and Control of Noncommunicable Diseases 2008-2013 Geneva: World Health Organization; 2008.

75. Gidding SS, Lichtenstein AH, Faith MS, Karpyn A, Mennella JA, Popkin B, Rowe J, Van Horn L, Whitsel L: Implementing American Heart Association pediatric and adult nutrition guidelines: a scientific statement from the American Heart Association Nutrition Committee of the council on nutrition, physical activity and metabolism, council on cardiovascular disease in the young, council on arteriosclerosis, thrombosis and vascular biology, council on cardiovascular nursing, council on epidemiology and prevention, and council for high blood pressure research. Circulation 2009, I 19:1 | 16I-II75.

76. Romon M, Lommez A, Tafflet M, Basdevant A, Oppert JM, Bresson JL, Ducimetière $P$, Charles MA, Borys JM: Downward trends in the prevalence of childhood overweight in the setting of I 2-year school- and community-based programmes. Public Health Nutr 2008:I-8. 